\title{
Anemia ferropénica severa secundaria a uncinarias
}

\section{Severe iron deficiency anemia secondary to uncinaria}

\author{
Adriana Catalina Uscátegui, Heison Joaquín Mora, \\ Milena del Pilar Castillo • Bogotá, D.C. (Colombia)
}

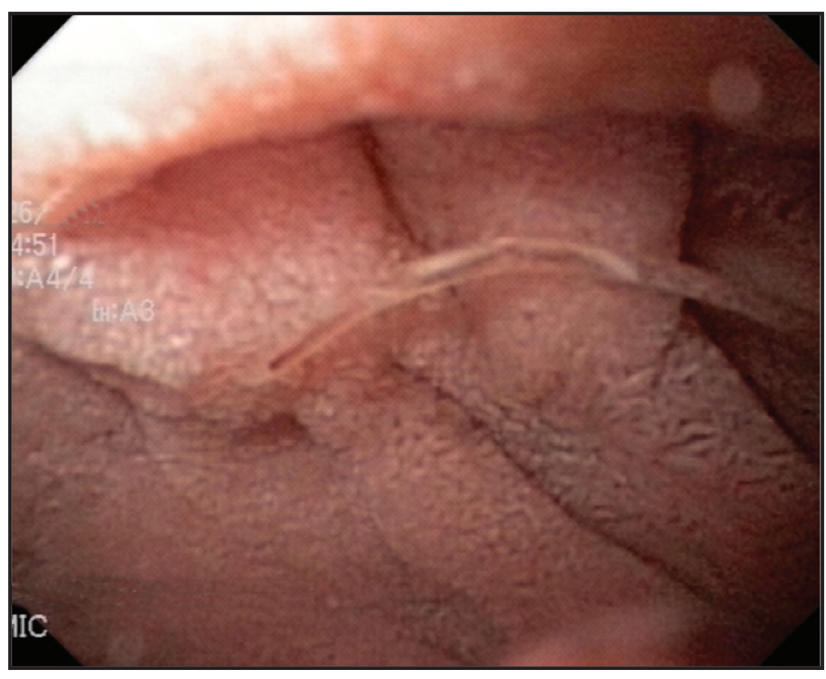

Ingresa paciente joven de 19 años, soldado, remitido del batallón por cuadro de un día de evolución, dado por astenia, adinamia y episodio de lipotimia mientras se encontraba realizando ejercicio físico, con posterior aparición de disnea leve; a su ingreso al servicio de urgencias del Hospital Militar Central con signos vitales dentro de límites normales, mucosas pálidas, sin otro hallazgo significativo en el examen físico, incluido tacto rectal negativo para sangrado. Se toman paraclínicos encontrado hemograma con hemoglobina de $5.5 \mathrm{~g} / \mathrm{dL}$, hematocrito $20 \%$ con volumen corpuscular medio de 59.7 fL, concentración de hemoglobina corpuscular media 15.9 pg, RDW $18.2 \%$ con recuento total de eosinófilos dentro de límites normales. Se hace diagnóstico de anemia microcítica hipocrómica.

Se realiza transfusión de dos unidades de glóbulos rojos, con remisión completa de los síntomas, dentro del estudio del síndrome anémico se realiza endoscopia de vías digestivas altas que muestra la presencia de múltiples larvas adultas de uncinarias, caracterizadas como Ancylostoma duodenale, se dio manejo con albendazol $400 \mathrm{mg}$, además de suplemento con sulfato ferroso.

La infección por uncinarias es causada por los helmintos Necator americanus y Ancylostoma duodenale es transmitida a través del contacto con suelo contaminado, y uno de sus mayores compromisos es la anemia ferropénica, por pérdidas gastrointestinales que resulta de la ruptura de capilares y ateriolas en unión del parásito a la pared intestinal (1).

\section{Referencias}

1. Hotez, Peter. Hookworm Infection. N Engl J Med 2004; 351: 799-807.
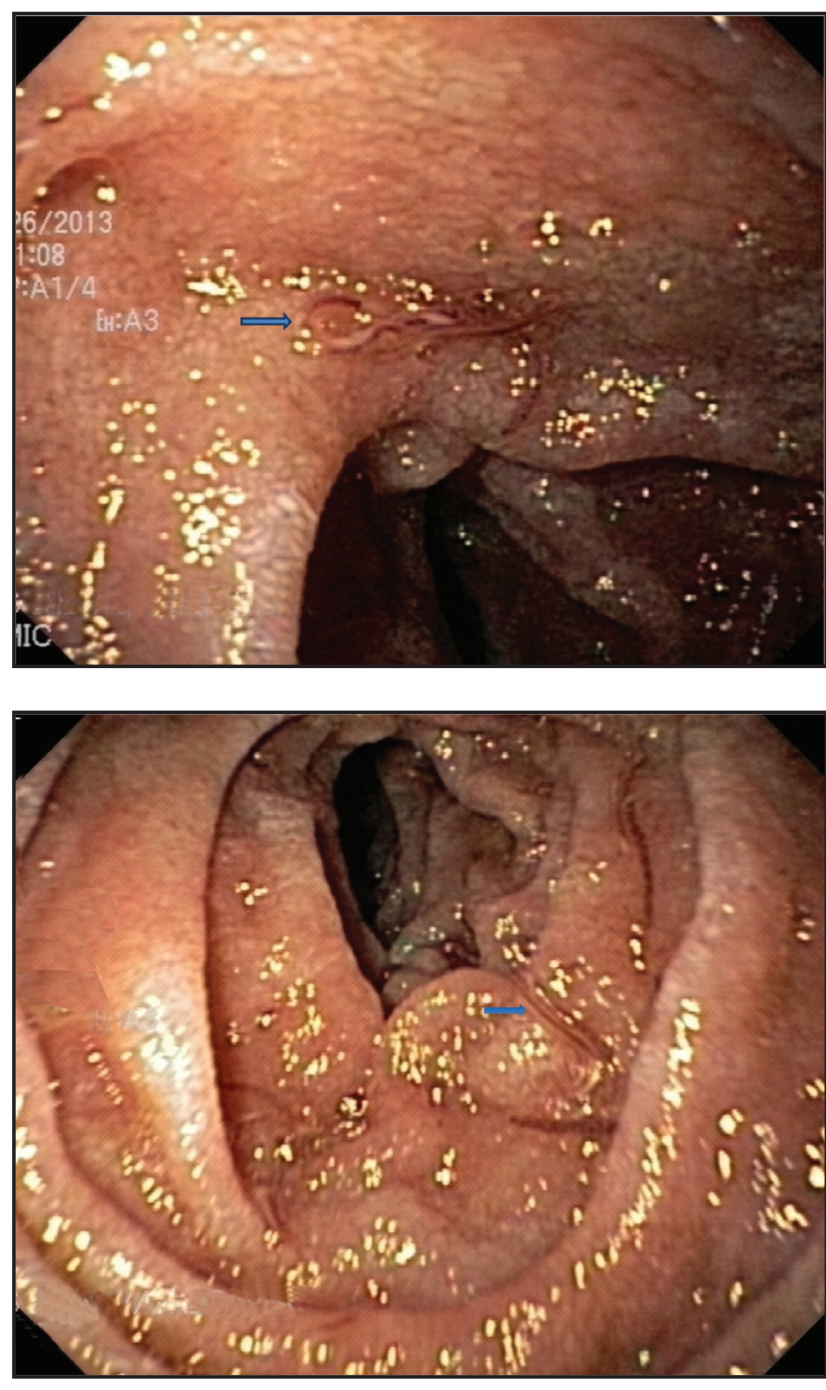

Dra. Adriana Catalina Uscátegui Ruiz: Cirujana Universidad Nacional de Colombia, Especialista en Medicina Interna Universidad del Rosario; Dr. Heison Joaquín Mora Buitrago: Cirujano Universidad Militar Nueva Grabada - HMC, Especialista en Medicina Interna Hospital Militar Central - UMNG, Fellow de Gastroenterología; Dra Milena del Pilar Castillo Mejía: Médico General Universidad de los Andes, Residente de Medicina Interna. Hospital Militar Central - Universidad Militar Nueva Granada. Bogotá, D.C. (Colombia).

Correspondencia. Dra. Adriana Catalina Uscategui Ruiz.

E-mail: acatalinamd@gmail.com

Recibido: 31/VII/2013 Aceptado: 25/IX/2013 